\title{
Использование лазерного излучения в хирургии хронического панкреатита
}

\begin{abstract}
Цель работы: изучить эффективность использования лазерных технологий при хирургическом лечении пациентов с хроническим панкреатитом.

Материалы и методы. В исследование включено 523 пациента, оперированных по поводу хронического панкреатита, в том числе 385 с резекционными операциями. С применением высокоэнергетического лазера “МУЛ-хирург” выполнено 131 хирургическое вмешательство, в т. ч. лазерную резекцию головки ПЖ - 84, лазерную цилиндрическую вирсунгэктомию - 25 , лазерные ДБЭ операции - 4 .

Результаты исследований и их обсуждение. Лазерные резекции ткани поджелудочной железы у пациентов с хроническим панкреатитом с использованием волны 1320 нм имеют достоверные преимущества перед электрокоагуляционным способом, заключающиеся в уменьшении кровопотери, снижении уровня тяжелых специфических послеоперационных осложнений. Имеется положительный опыт использования лазерных технологий при выполнении эндоскопических операций с применением двухбаллонного энтероскопа для коррекции послеоперационных осложнений в зоне панкреатоеюноанастомозов. Использование лазерного излучения в хирургии хронического панкреатита является перспективным направлением в хирургической панкреатологии
\end{abstract}

Ключевые слова: хронический панкреатит; хирургический лазер; лазерная резекция; вирсунгэктомия; двухбаллонная энтероскопия.

Постановка проблемы и анализ последних исследований и публикаций. Под хроническим панкреатитом (ХП) понимают воспалительный процесс, который приводит к прогрессирующей и необратимой деструкции экзокринных и эндокринных клеток поджелудочной железы (ПЖ) с последующим замещением их фиброзной тканью, необратимым изменениям протоковой системы. Наиболее эффективными в коррекции осложнений хронического панкреатита признаны резекционно-дренирующие операции [1, 2].

Несмотря на длительность использования данных типов операций, совершенствование хирургических технологий, количество послеоперационных осложнений и летальность остаются на высоком уровне. Летальность при выполнении резекционных операций на ПЖ составляет 1-3 \%. При этом уровень послеоперационных осложнений может достигать 20-50 \% [3, 4, 5, 6, 7]. При проведении всех видов операций требуется рассечение ткани ПЖ с обеспечением хорошего гемостаза и минимальным уровнем повреждений сохраняемой ткани ПЖ ввиду необходимости ее последующего анастомозирования с тонкой кишкой. Вследствие этого данные операции имеют свои специфические осложнения, диагностика и коррекция которых представляет серьезные трудности: послеоперационный панкреатит, несостоятельность панкреатикодигестивных анастомозов, интестинальные кровотечения. Наиболее опасными осложнениями, безусловно, являются кровотечения из зоны панкреатоеюноанастомоза (ПЕА) и несостоятельность ПЕА, которые зачастую сочетаются.

Наряду с разработками новых хирургических операций и технологий, улучшением диагностики, предоперационной подготовки, интенсивной терапии, поиск новых подходов в обеспечении гемостаза после резекции ПЖ и методов профилактики несостоятельности ПЕА являются актуальной проблемой хирургии. Наряду с традиционными методами гемостаза, такими как лигирование и прошивание кровоточащих сосудов, моно- и биполярная коагуляция, ультразвуковая коагуляция, перспективным направлением является использование лазерного излучения для резекции и гемостаза ткани ПЖ. При этом оказывается минимальное повреждающее действие на прилежащие ткани.

Биологические ткани после лазерного рассечения имеет меньшую глубину некроза и теплового повреждения и обладают способностью к быстрому заживлению. Положительным фактором использования лазерного излучения является то, что процесс заживления лазерных ран отличается от аналогичного в ранах, нанесенных с помощью скальпеля и электрокоагуляции. Он обладает более короткой фазой воспаления, меньшей экссудацией и лейкоцитарной инфильтрацией. При этом раньше образуется полноценная грануляционная и соединительная ткань [8]. 
Первое сообщение о применении лазеров в хирургии органов брюшной полости в эксперименте сделано L. Goldman [9]. О. К. Скобелкин и Е. И. Брехов выявили феномен лазерной “сварки” всех слоев стенок органов желудочно-кишечного тракта [10]. Отмечается 5 основных типов воздействия лазерного излучения на биологические ткани: фотохимическое - активация физико-химических процессов в биологических тканях; фотокоагуляция белков при повышении температуры ткани свыше $60{ }^{\circ} \mathrm{C}$; фотоиспарение при повышении температуры до $300{ }^{\circ} \mathrm{C}$; фотоаблация - взрывное удаление ткани из-за быстрого поглощения энергии в тонком слое; ударное разрушение, которое происходит в результате оптического пробоя в прозрачной биоткани [11]. Механизм воздействия лазеров состоит в нагреве биологических тканей при поглощении излучения. Рассечение происходит за счет послойного испарения ткани. По линии лазерного разреза нет микробов и отделившихся клеток, блокируются кровеносные и лимфатические сосуды. В основе гемостатического эффекта лежит коагуляция стенок сосу- дов и форменных элементов крови с образованием тромба. Лазеры стали широко применяться в экстренной и плановой абдоминальной хирургии, однако в литературе имеются единичные сообщения об использовании лазерного излучения в хирургии поджелудочной железы. В основном это касается использования расфокусированного излучения для обработки очагов панкреанекроза и использования $\mathrm{CO}_{2}$-лазера для коагуляции ткани поджелудочной железы при ХП [12]. Появление высокоэнергетических лазеров с гибкими световодами, возможностью использования различных длин волн значительно расширяет возможности применения лазерных технологий в хирургии поджелудочной железы [13].

Материалы и методы. С 2010 по 2019 годы в клинике оперировано 523 пациентов с ХП. У них выполнены 48 резекционных операций. 94 - дренирующих операций, 45 - шунтирующие операции. Основную массу операций (337) составили проксимальные дуоденосохраняющие резекции ПЖ в различных вариантах (табл. 1).

Таблица 1. Наш опыт в хирургии хронического панкреатита (2010-2019 гг.)

\begin{tabular}{|c|c|c|}
\hline Тип операции & Всего & В том числе \\
\hline $\begin{array}{l}\text { Резекционные } \\
\text { ПДР } \\
\text { Дистальная резекция } \\
\text { Центральная резекция }\end{array}$ & 48 & $\begin{array}{c}20 \\
25 \\
3\end{array}$ \\
\hline $\begin{array}{l}\text { Дренирующие } \\
\text { Partington - Rochelle } \\
\text { Partington - Rochelle лапароскопические } \\
\text { Partington - Rochelle + цистоэнтеростомия } \\
\text { Partington - Rochelle + вирсунгэктомия } \\
\text { ПГА }\end{array}$ & 94 & $\begin{array}{c}43 \\
2 \\
27 \\
9 \\
12\end{array}$ \\
\hline $\begin{array}{l}\text { Резекционно-дренирующие } \\
\text { Операция Frey } \\
\text { - экстрапанкреатичный ГЕА } \\
\text { Операция Izbicki } \\
\text { Операция Beger } \\
\text { Бернский вариант операции Beger } \\
\text { - продольная панкреатовирсунготомия в теле ПЖ } \\
\text { - цилиндрическая вирсунгэкомия в теле ПЖ } \\
\text { - иссечение тела ПЖ по типу Izbicki } \\
\text { - внутренняя ХПС } \\
\text { - дренирование ПЕА через пузырный проток }\end{array}$ & $\begin{array}{l}337 \\
101 \\
10 \\
2 \\
223\end{array}$ & $\begin{array}{l}71 \\
49 \\
12 \\
77 \\
65\end{array}$ \\
\hline $\begin{array}{l}\text { Шунтирующие } \\
\text { Билиарная декомпрессия } \\
\text { Операции при дуоденальной непроходимости }\end{array}$ & 45 & $\begin{array}{l}33 \\
12\end{array}$ \\
\hline Всего & 523 & \\
\hline
\end{tabular}


Из 523 операций при ХП 3385 выполнено с резекций ПЖ. Резекцию паренхимы головки и тела ПЖ выполняли двумя методами: традиционно с использованием моно- и биполярной коагуляции и дополнительным лигированием ветвей панкреатодуоденальных артерий $(\mathrm{n}=249)$ и с использованием высокоэнергетического лазерного излучения $(\mathrm{n}=82)$. В качестве источника лазерного излучения использовали лазерную установку МУЛ-хирург производства “ТЕТРАЭДР” (Республика Беларусь) (рис. 1). В этом аппарате применена одна твердотельная лазерная система на гранатовой активной среде, работающая в импульсночастотном режиме и генерирующая три различных по своим свойствам рабочих лазерных луча с длинами волн 1064 нм, 1320 нм и 1440 нм с возможностью их быстрого переключения и максимальной выходной энергией импульсов излучения до 4 Дж и выходной средней мощность излучения до 100 Вт (табл. 2). Транспортировка лазерного излучения осуществляется с помощью гибкого световода. Тип применяемого световода - кварцевый, ступенчатого типа диаметром 0,6 мм, 0,5 мм, 0,4 мм, 0,3 мм. Выходной лазерный инструментарий - дистальный конец световода со специальными насадками. В лазерном аппарате реализованы режимы “приоритет коагуляция” и “приоритет рассечение”. Во всех наблюдениях использовали световодный инструмент диаметром 600 мкм.

При выполнении резекции ПЖ, как правило, использовали лазерное излучение с длиной волны 1,32 мкм и мощностью 36-45 Вт в режиме коагуляции.

Проведено сравнительное морфологическое исследование образцов ткани ПЖ, полученных в ходе резекционных оперативных вмешательств у пациентов с ХП с использованием коагуляции (n-20) и с применением лазерного излучения (n-20). Образцы ткани ПЖ обрабатывали по стандартной методике, окрашивали гематоксилином-эозином и трихромом. Изучение препаратов и изготовление микрофотографий проводили с помощью световых микроскопов AxioImager (Zeiss, Германия)

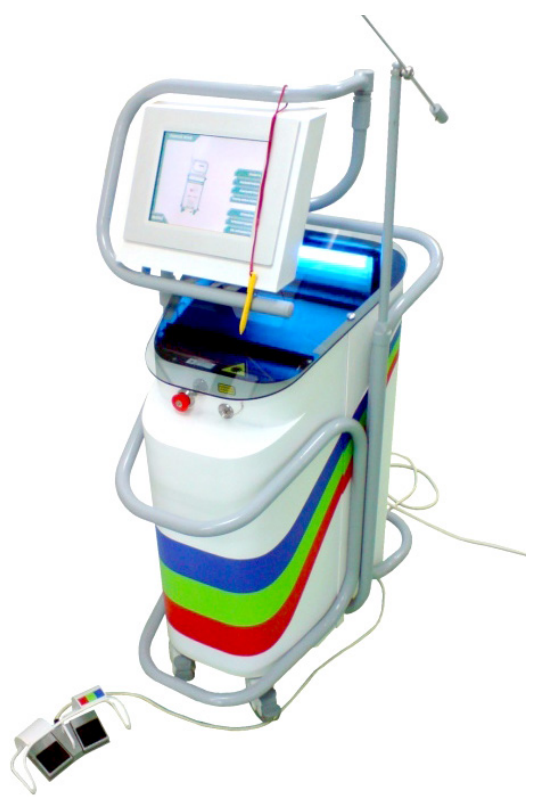

Рис. 1. Лазерная система МУЛ-хирург.

и DMLS (“Leica”, Германия). Морфометрический анализ и статистическую обработку результатов проводили при помощи програмно-аппаратного комплекса "Leica-Qwin".

Разработана, запатентована и выполнена ( $=58)$ операция “цилиндрическая вирсунгэктомия” для ликвидации панкреатической протоковой гипертензии в теле поджелудочной железы, в т. ч. в лазерном исполнении $(\mathrm{n}=25)$ [14].

В период 2010-2019 годы проведено 27 трансоральных (антеградных) исследований двухбаллонным энтероскопом (ДБЭ) просвета ПЕА через петлю Ру. При этом для выполнения хирургических малоинвазивных манипуляций в зоне ПЕА (вапоризация стриктур, литотрипсия панкреатолитов) использовали лазер “МУЛ-хирург” (Республики Беларусь). Применяли лазерное излучение с длиной волны 1,32 мкм и мощностью 15-30 Вт.

Статистическая обработка результатов исследования проводилась с использованием пакета статистических программ "STATISTICA 10.0" (Version 10-Index, StatSoftInc, США). Представле-

Таблица 2. Основные технические характеристики лазерной установки МУл-хирург

\begin{tabular}{||c|c|c|c|c||}
\hline $\begin{array}{c}\text { Длины волн лазерного } \\
\text { излучения, (мкм) }\end{array}$ & $\begin{array}{c}\text { Максимальная выходная } \\
\text { энергия импульсов } \\
\text { излучения (Дж) }\end{array}$ & $\begin{array}{c}\text { Выходная средняя } \\
\text { мощность } \\
\text { излучения (Вт) }\end{array}$ & $\begin{array}{c}\text { Частота } \\
\text { следования } \\
\text { импульсов (Гц) }\end{array}$ & $\begin{array}{c}\text { Длительность } \\
\text { лазерных } \\
\text { импульсов (мс) }\end{array}$ \\
\hline 1,064 & 4 & до 100 & до 100 & $0,5-2$ \\
\hline 1,32 & 2 & до 60 & до 75 & $0,5-2$ \\
\hline 1,44 & 0,9 & до 25 & до 55 & $0,5-2$ \\
\hline
\end{tabular}


ние результатов в виде медианы, верхнего и нижнего квартилей (Ме; 25-й; 75-й процентиль). Достоверным считалось различие при уровне значимости $\mathrm{p}<0,05$.

Результаты исследований и их обсуждение. При морфологическом изучении зон термического повреждения ткани ПЖ при воздействии электрокоагуляции установлено, что слой коагуляции неравномерно широкий, встречаются значительные по протяженности участки карбонизации. В объемных зонах термического поражения (ТП) часто формируются полиморфные тонкостенные открытые внутренние вапоризационные полости (ВП) (рис. 2). У ряда пациентов обнаруживаются

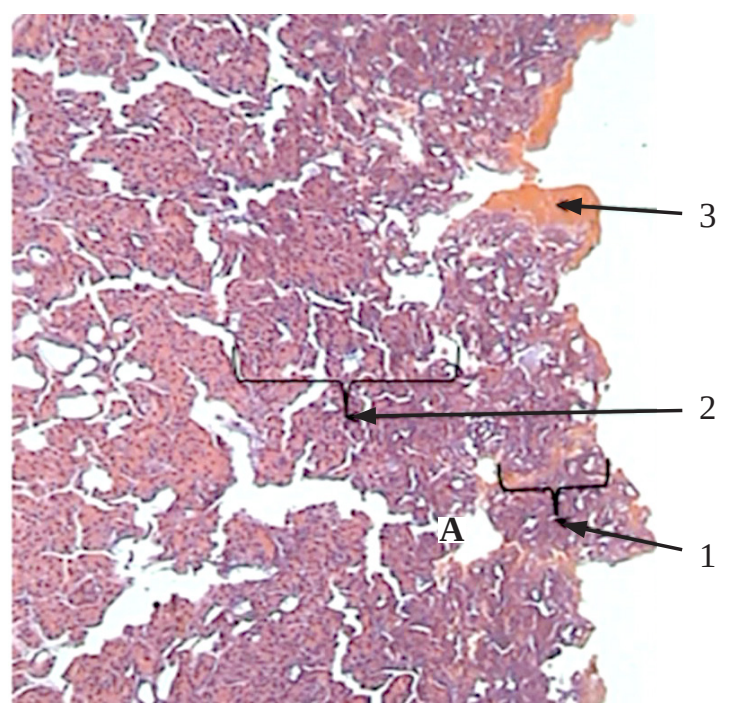

Рис. 2. Электрокаогуляционная резекция поджелудочной железы: 1 - зона коагуляции-вапоризации; 2 перифокальная зона; 3 - зона карбонизации (гематоксилин-эозин, ×200).

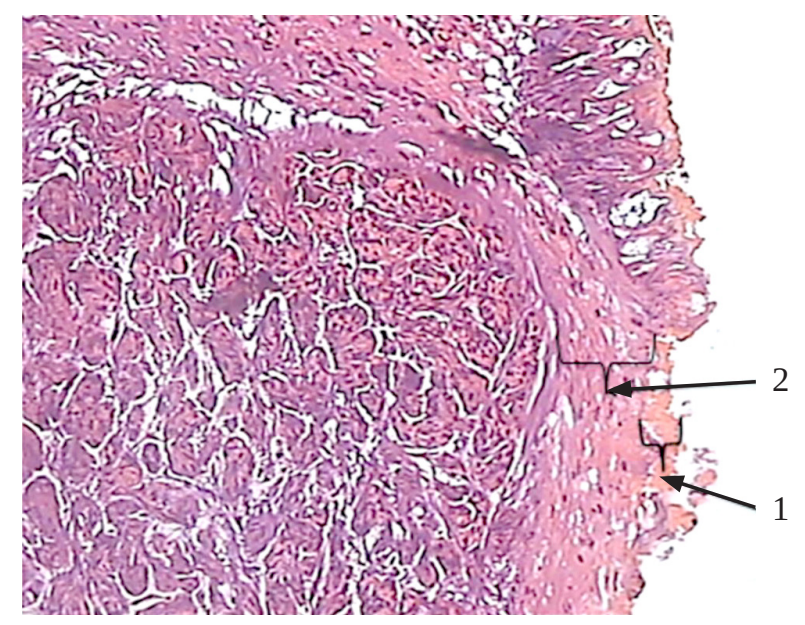

Рис. 3. Лазерная резекция поджелудочной железы: 1 - зона коагуляции-вапоризации; 2 - перифокальная зона (гематоксилин-эозин, ×200). объемные участки полосовидных кровоизлияний.

В ткани ПЖ пациентов, оперированных с использованием высокоэнергетического лазера, слой коагуляции поверхностный, всегда непрерывный, неравномерный, гомогенного вида, бесструктурный (рис. 3). ВП мелкие, узкие, гладкостенные и без содержимого, всегда закрытого типа. В зоне предкоагуляционных изменений отмечается выпаривание основного вещества экстрацеллюлярного матрикса, за счет чего наблюдается констрикция зоны склероза (рис. 4), запаивание мелких сосудов свернувшейся кровью или коагуляционным детритом. В крупных сосудах отмечается сужение просвета, очаговая коагуляция эндотелиальной выстилки (рис. 5).

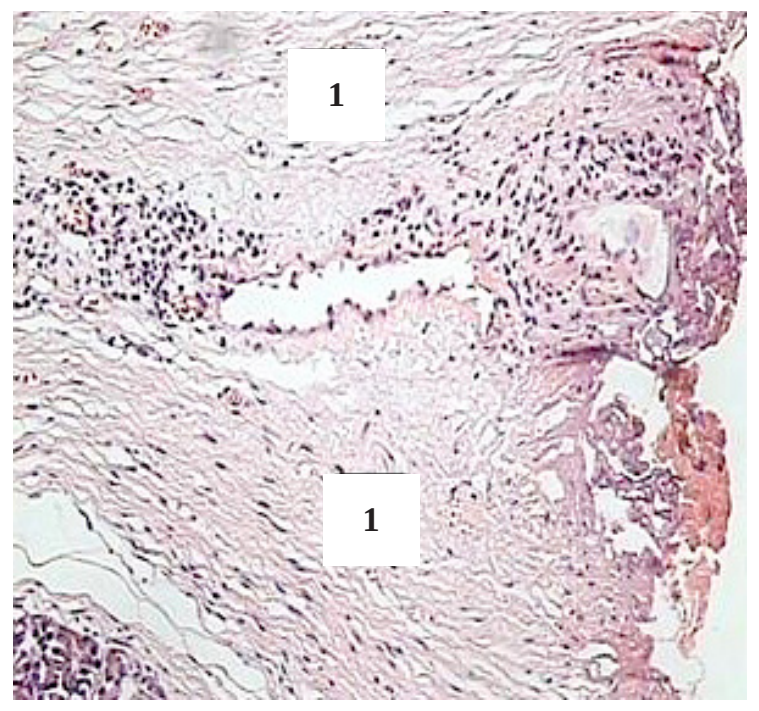

Рис. 4. Лазерная резекция поджелудочной железы: выпаривание межклеточного вещества (1) в соединительнотканных прослойках перифокальной зоны (гематоксилин-эозин, ×200).

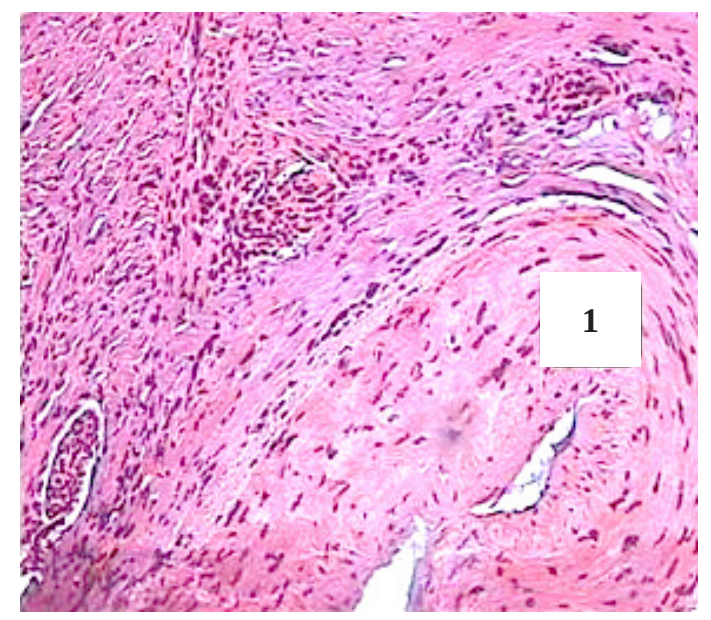

Рис. 5. Лазерная резекция поджелудочной железы: констрикция артерии (1) перифокальной зоны (гематоксилин-эозин, ×200). 
При морфометрическом исследовании отмечено значительное $(\mathrm{p}<0,05)$ уменьшение глубины зоны ТП у пациентов, оперированных с использованием лазера, по сравнению с моно- и биполярной коагуляцией (табл. 3).

В клинике лазерное излучение при хирургическом лечении использовано у 105 пациентов, выполнено 127 вмешательства (табл. 4).

Лазерное иссечение головки ПЖ при выполнении резекционно-дренирующих операций позволило обеспечить стойкий, надежный гемостаз, уменьшить объем кровопотери при выполнении резекции головки ПЖ 181 (90; 320) мл по сравнению с техникой гемостаза с использованием электрокоагуляции $302(210 ; 580)$ мл. При этом не требовалось дополнительного лигирования сосудов или прошивания ткани железы. Одним из специфических свойств лазерного излучения является вапоризация обрабатываемых тканей. В предложенном варианте лазерного иссечения головки ПЖ происходило уплотнение ткани железы по краю резекции, что облегчало формирование ПЕА, повышало его герметичность.

Послеоперационные осложнения при электрохирургической технике резекции ПЖ, включая желудочно-кишечные кровотечения, отмечены в достоверно большем количестве случаев (19,3 \%), чем при лазерной технологии резекции ПЖ (14,6 \%). Релапаратомии выполнялись в 6 случаях (2,4 \%) после электрокоагуляционного способа резекции, в то время как после лазерного способа резекции - в 1 случае (1,2 \%) (табл. 5).

Таблица 3. Зоны термического повреждения при различных способах резекции поджелудочной железы, мкм

\begin{tabular}{||l|c|c|c||}
\hline \hline Способ резекции & Зона коагуляции-вапоризации & Перифокальная зона & Зона термического повреждения \\
\hline Электрокоагуляция & $561(264-799)$ & $143(113-181)$ & $705(456-919)$ \\
\hline Лазер & $347(232-520)^{*}$ & $63(44-85)^{*}$ & $410(287-569)^{*}$ \\
\hline \hline
\end{tabular}

Примечание: * $\mathrm{p}<0,05$ по сравнению с электрокоагуляционной резекцией.

Таблица 4. Наш опыт лазерных операций на поджелудочной железе у пациентов с хроническим панкреатитом

\begin{tabular}{||l|c||}
\hline \hline \multicolumn{1}{||c|}{ Вид вмешательства } & Количество пациентов, $\mathrm{n}$ \\
\hline Лазерная резекция головки ПЖ & 84 \\
\hline Лазерная цилиндрическая вирсунгэктомия & 26 \\
\hline Лазерные ДБЭ операции & 4 \\
\hline Другие (панкреатовирсунготомия, лазерный гемостаз) & 17 \\
\hline Всего & 131 \\
\hline \hline
\end{tabular}

Таблица 5. Сравнение результатов электрокоагуляционного и лазерного способов резекции поджелудочной железы

\begin{tabular}{|c|c|c|}
\hline Основные показатели & $\begin{array}{c}\text { Электрокоагуляционный } \\
\text { способ }(\mathrm{n}=301)\end{array}$ & Лазерный способ (n=84) \\
\hline Кровопотеря, мл & $290(120 ; 580)$ & $180(80 ; 320)$ \\
\hline Гемостаз & $\begin{array}{c}\text { Требуется дополнительное } \\
\text { лигирование }\end{array}$ & Полный \\
\hline Коагуляционный струп в зоне резекции & Грубый, глубокий & Нежный, поверхностный \\
\hline Послеоперационные осложнения (n, \%) & $55(18,2)$ & $12(14,2)^{*}$ \\
\hline Ограниченный некроз ДПК (n, \%) & $4(1,3)$ & $-*$ \\
\hline Послеоперационные кровотечения из ложа ПЖ (n, \%) & $12(4,0)$ & $2(2,4) *$ \\
\hline Другие осложнения (n, \%) & $39(12,9)$ & $10(11,9)$ \\
\hline
\end{tabular}


Интересным представляется опыт трех случаев ограниченных некрозов медиальной стенки двенадцатиперстной кишки. По нашему мнению, причиной их является ишемическое и коагуляционное повреждение стенки кишки при субтотальной резекции головки ПЖ. Манифестируется данное осложнение желудочно-кишечным кровотечением, диагностируется при ФГДС. В лечебном алгоритме достаточно консервативных мероприятий, ввиду того что дефект кишки открывается в полость ПЕА, дополнительно дренируя ее. Основной опасностью является то обстоятельство, что при параллельном развитии несостоятельности ПЕА может формироваться общий панкреатодуоденальный свищ. В наших наблюдениях развитие ограниченных некрозов медиальной стенки двенадцатиперстной кишки произошло только в случаях выполнения проксимальных резекций головки с помощью электрокоагуляции. В случаях выполнения лазерных резекций этих осложнений не было зарегистрировано, что объясняется различными зонами теплового повреждения тканей.

В клинике разработана и внедрена операция цилиндрической вирсунгэктомии (n-58). Операция заключается в ликвидации панкреатической
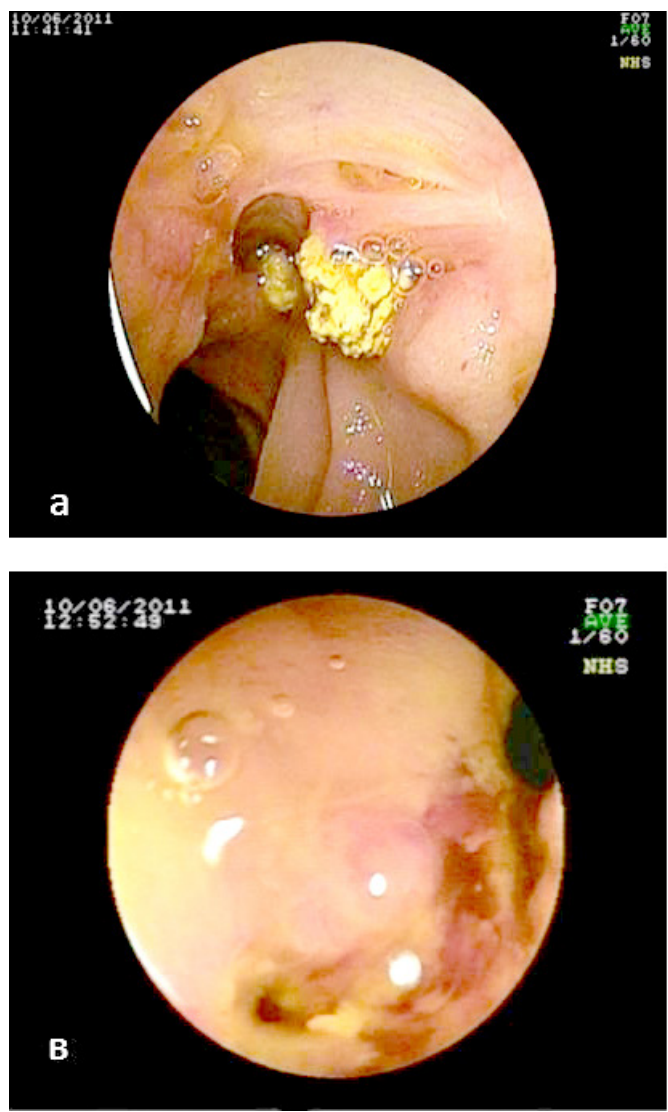

гипертензии в протоках 2-3 порядка левого сектора (тело-хвост) ПЖ, когда после выполнения панкреатовирсунготомии проводится иссечение Вирсунгова протока в теле поджелудочной железы с окружающей на 2-3 мм проток тканью железы, что позволяет эффективно восстанавливать пассаж панкреатического сока из панкреатических протоков 2-3 порядка, тем самым ликвидируя периферическую панкреатическую гипертензию. Данное вмешательство чаще применялось в сочетании с резекцией головки ПЖ (n-40), в 6 случаях использована как самостоятельная операция. Цилиндрическая вирсунгэктомия выполнялась с помощью электрокоагулятора (n-32) и лазерного излучения (n-26). При использовании электрокоагуляции отмечено 3 случая интраоперационного кровотечения из селезеночных сосудов. При применении лазерного варианта этого вмешательства случаев интраоперационных кровотечений не отмечено.

Использование лазерных технологий при ДБЭисследовании панкреатоеюноанастомзов. 27 пациентам с использованием ДБЭ был проведен трансоральный (антеградный) осмотр ПЕА через петлю тощей кишки по Ру. Производили визуальный осмотр зоны соустья, по показаниям бра-
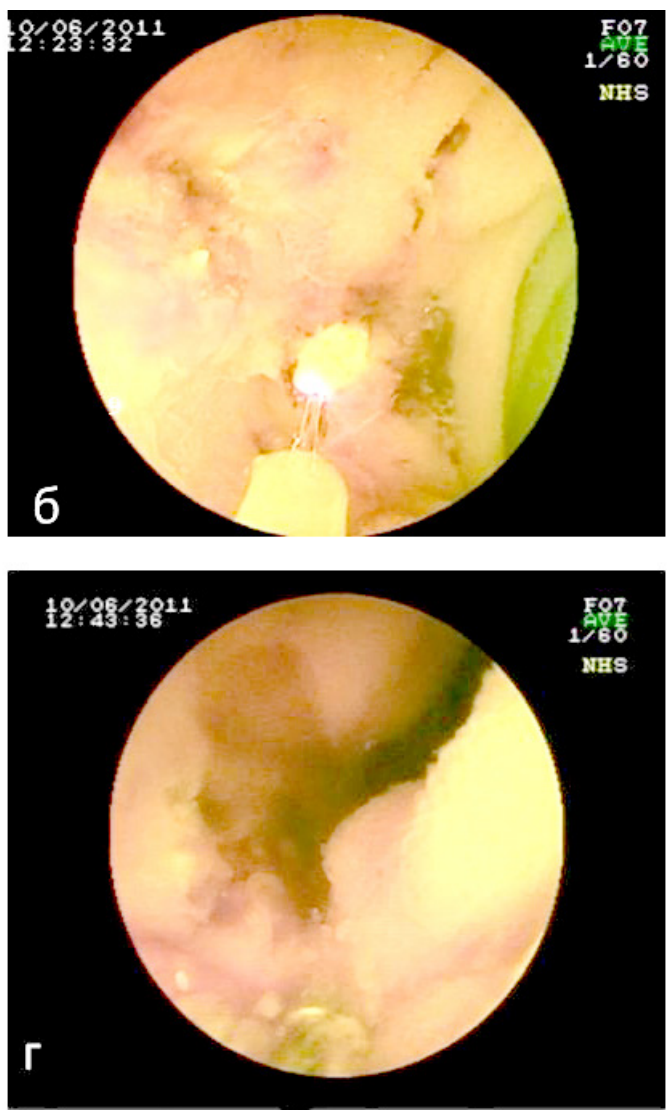

Рис. 6. ДБЭ: лазерная литотрипсия остаточного конкремента в просвете ПЕА: а - конкремент в области сформированной ХПС, б - литотрипсия, в - широкая ХПС; г - восстановился желчеотток. 
ли биопсию из стенки петли тощей кишки по Ру и поджелудочной железы. Возраст пациентов варьировал от 32 до 65 лет. Сроки выполнения ДБЭ после первичной операции составили от 3 мес. до 2 лет. Среднее время ДБЭ-осмотра петли тощей кишки и панкреатодигестивного анастомоза составило 85 (55;120) мин.

Зону ПЕА удалось осмотреть в 20 наблюдениях. В 11 наблюдениях была выявлена послеоперационная патология ПЕА: стриктура ПЕА и ХПС $(\mathrm{n}=2)$, несостоятельность ПЕА (n=1), остаточные конкременты в области ПЕА ( $\mathrm{n}=5)$, кровотечение из зоны ПЕА (n=1), Выполнены 4 малоинвазивные ДБЭ-операции в зоне ПЕА с применением лазера: лазерная литотрипсия (n=2) (рис. 6), лазерный гемостаз кровотечения из зоны ПЕА, лазерная вапоризация стриктуры $(\mathrm{n}=1)$. Осложнений после проведения процедур не было.

Заключение. Резекция ПЖ у пациентов с ХП с использованием коагуляции и высокоэнергетического лазера сопровождается формированием зон коагуляции-вапоризации и перифокальной зоны. При использовании коагуляции зона теплового повреждения достоверно значительно обширнее, чем при использовании лазерного излучения. При применении моно- и биполярной коагуляции в зоне теплового повреждения чаще отмечаются кровоизлияния, открытые вапоризационные полости и очаги карбонизации, чем при использовании лазерного излучения. Выпаривание основного вещества экстрацеллюлярный матрикс, за счет чего наблюдается констрикция (уплотнение) зоны склероза при использовании лазерного излучения создает условия для формирования более надежных ПЕА по завершению резекции ПЖ. В перифокальной зоне в случае использования лазерного излучения наблюдаются констрикция зон склероза, при электрокоакуляционном способе резекции указанного эффекта не наблюдалось. Установленные эффекты высокоэнергетического лазерного излучения могут способствовать предупреждению развития тяжелых послеоперационных осложнений (послеоперационного панкреатита, кровотечения, несостоятельности ПЕА) при резекции ПЖ.

Лазерная резекция ткани ПЖ при ее проксимальной резекции с использованием волны 1320 нм имеет достоверные преимущества перед электрокоагуляционным способом, заключающиеся в уменьшении кровопотери, снижении уровня тяжелых послеоперационных осложнений. Исходя из нашего опыта, лазерные резекции ПЖ имеют следующие преимущества перед традиционными электрохирургическими:

a) полный гемостаз без дополнительного лигирования или клипирования, что сокращает время операции, уменьшает объем кровопотери;

б) образующийся нежный струп на поверхности ПЖ, эффект лазерной кавитации и литотрипсии способствуют визуализации во время операции и отхождению после операции в просвет ПЕА мелких конкрементов из периферических протоков 2-3 порядка;

в) уплотнение ткани ПЖ после лазерной резекции повышает надежность продольного ПЕА.

Разработанная и внедренная в клинике операция лазерного иссечения главного панкреатического протока в теле железы вместе с цилиндрическим иссечением ткани железы вокруг протока - “цилиндрическая вирсунгэктомия" - позволяет эффективно восстанавливать пассаж панкреатического сока из панкреатических протоков 2-3 порядка, с ликвидацией “периферической панкреатической гипертензии”.

ДБЭ продемонстрировала большие возможности в диагностике поздних осложнений резекционно-дренирующих операций на ПЖ, позволяет объективизировать причины возобновления абдоминалгии, оценить эффективность различных типов первичных хирургических вмешательств при ХП. С применением лазерных технологий существенно расширяются операционные возможности ДБЭ для коррекции осложнений в послеоперационном периоде, включая лазерную литотрипсию остаточных панкреатолитов, гемостаз, рассечение стриктур. Лазерная литотрипсия остаточных конкрементов с использованием ДБЭ является эффективным малоинвазивным методом коррекции осложнений после формирования ПЕА.

Трехволновая лазерная система МУЛ-хирург (Тэтраэдр, РБ) позволяет эффективно выполнять комплекс сложных хирургических вмешательств на ПЖ при хроническом панкреатите, включая резекцию ткани ПЖ в сочетании хорошим гемостазом, интраоперационную и послеоперационную литотрипсию панкреатолитов. 


\section{СПИСОК ЛИТЕРАТУРЫ}

1. Frey C. F. Comparison of local resection of the head of the pancreas combined with longitudinal pancreaticojejunostomy (Frey procedure) and duodenum-preserving resection of the pancreatic head (Beger procedure) / C. F. Frey, L. M. Kathrin // World J. Surg. - 2003. - Vol. 27. - P. 1217-1230.

2. Changes in mortality after pancreatic resection: towards the end of completion pancreatectomy / M. W. Büchler, M. Wagner, B. M. Schmied [et al.] // Arch. Surg. - 2003. - Vol. 138. P. 1310-1314.

3. Octreotide in the prevention of intra-abdominal complications following elective pancreatic resection: A prospective, multicenter randomized controlled trial / B. Sue, S. Msika, M. Piccinini [et al.] // Arch. Surg. - 2004. - Vol. 139. - P. 288-294.

4. Risk factors for complications after pancreatic head resection / U. Adam, F. Makowiec, H. Riediger [et al.] // Am. J. Surg. 2004. - Vol. 187. - P. 201-208.

5. Postpancreatectomy hemorrhage $(\mathrm{PPH})$ : predictors and management from a prospective database / B. Darnis, R. Lebeau, X. Chopin-Laly, M. Adham // Langenbecks Arch. Surg. - 2013. Vol. 398, No. 3. - P. 441-448.

6. Pancreatic fistula after pancreatichead resection / M. W. Büchler, H. Friess, M. Wagner [et al.] // Br. J. Surg. - 2000. - Vol. 87. P. 883-889.

7. Шхастный А. Т. Послеоперационные осложнения проксимальных резекций поджелудочной железы у пациентов с хроническим панкреатитом / А. Т. Шхастный // Новости

\section{REFERENCES}

1. Frey, C.F., \& Kathrin, L.M. (2003). Comparison of local resection of the head of the pancreas combined with longitudinal pancreaticojejunostomy (Frey procedure) and duodenum-preserving resection of the pancreatic head (Beger procedure). World $J$. Surg., 27, 1217-1230.

2. Büchler, M.W., Wagner, M., Schmied, B.M., Uhl, W., Friess, H., \& Z'graggen, K. (2003). Changes in mortality after pancreatic resection: towards the end of completion pancreatectomy. Arch. Surg., 138, 1310-1314.

3. Sue, B., Msika, S., Piccinini, M., Fourtanier, G., Hay, J.M., Flamant, Y., Fingerhut, A., Fagniez, P.L., \& Chipponi, J. (2004). Octreotide in the prevention of intra-abdominal complications following elective pancreatic resection: A prospective, multicenter randomized controlled trial. Arch. Surg., 139, 288-294.

4. Adam, U., Makowiec, F., Riediger, H., Schareck, W.D., Benz, S., \& Hopt U.T. (2004). Risk factors for complications after pancreatic head resection. Am. J. Surg., 187, 201-208.

5. Darnis, B., Lebeau, R., Chopin-Laly, X., \& Adham, M. (2013). Postpancreatectomy hemorrhage (PPH): predictors and management from a prospective database. Langenbecks Arch. Surg., 398 (3), 441-448

6. Büchler, M.W., Friess, H., Wagner, M., Kulli, C., Wagener, V., \& Z'Graggen, K. (2000). Pancreatic fistula after pancreatichead resection. Br. J. Surg., 87, 883-889.

7. Shhastnyy, A.T. (2011). Posleoperatsionnye oslozhneniya proksimalnykh rezektsiy podzheludochnoy zhelezy u patsieyntov s khronicheskim pankreatitom [Postoperative complications of proximal pancreatic resection in patients with chronic pancreatitis]. Novosti khirurgii - News of Surgery, 19 (3), 30-43 [in Russian]. хирургии. - 2011. - Т. 19, Вып. 3. - С. 30-43.

8. Елисеенко В. И. Особенности репаративных процессов органов желудочно-кишечного тракта при воздействии непрерывного лазерного излучения / В. И. Елисеенко, О. К. Скобелкин, Е. И. Брегов // Весник АМН СССР. - 1985. - № 7. - C. 72 -78.

9. Goldman L. Current and future developments in laser surgery / L. Goldman // Surg. Clin. N. Amer. - 1984. - Vol. 64, No. 5. P. 1001-1012.

10. Скобелкин О. К. Лазеры в хирургии / Под ред. О. К. Скобелкина. - М. : Медицина, 1989. - 256 с.

11. Soklakov A. I. Laser / A. I. Soklakov // Market. - 1993. Vol. 6. - P. 14-15.

12. Корепанов В. И. Применение Nd:YAG лазера в хирургической клинике: практическое руководство / В. И. Корепанов // Рос. мед. акад. последиплом. образования.- М., 1996. -108 c.

13. Использование высокоэнергетического лазера в гепатопанкреатобилиарной хирургии / А. В. Воробей, А. Ч. Шулейко, И. Н. Гришин [и др.] // Український журнал хірургії. 2013. - № 3. - С. 63-69.

14. Патогенетическое обоснование первичных и повторных операций на поджелудочной железе при хроническом панкреатите / А. В. Воробей, И. Н. Гришин, А. Ч. Шулейко [и др.] // Анналы хирургической гепатологии. - 2012. - № 3. C. $80-88$.

8. Eliseenko, V.I., Skobelkin, O.K., \& Bregov, E.I. (1985). Osobennosti reparativnykh protsessov organov zheludochno-kishechnogo trakta pri vozdeystvii nepreryvnogo lazernogo izlucheniya [Features of reparative processes of the gastrointestinal tract when exposed to continuous laser radiation]. Vestnik AMN SSSR - Bulletin of AMS USSR, 7, 72-78 [in Russian].

9. Goldman, L. (1984). Current and future developments in laser surgery. Surg. Clin. N. Amer., 64 (5), 1001-1012.

10. Skobelkin, O.K. (1989). Lazery v khirurgii [Lazers in surgery]. Moscow: Meditsina [in Russian].

11. Soklakov, A.I. (1993). Laser. Market., 6, 14-15.

12. Korepanov, V.I. (1996). Primenenie Nd: YAG lazera v khirurgicheskoy klinike: prakticheskoe rukovodstvo [Nd: YAG laser applications in a surgical clinic: A practical guide]. Moscow: Russian Medical Academy of Postgraduate Education [in Russian]. 13. Vorobey, A.V., Shuleyko, A.Ch., Grishin, I.N., Orlovskiy, Yu.N., Ilyushonok, V.V., Aleksandrov, S.V., Butra Yu.V., \& Lagodich, N.A. (2013). Ispolzovanie vysokoenergeticheskogo lazera $\mathrm{v}$ gepatopankreatobiliarnoy khirurgii [The use of high-energy laser in hepatopancreatobiliary surgery]. Ukrainskiy zhurnal khirurgii - Ukrainian Journal of Surgery, 3, 63-69 [in Russian].

14. Vorobey, A.V., Grishin, I.N., Shuleyko, A.Ch., Butra, Yu.V., Lurye, V.N., Orlovskiy, Yu.N., Vizhinis, E.I., Aleksandrov, S.V., \& Lagodich, N.A. (2012). Patogeneticheskoe obosnovanie pervichnykh i povtornykh operatsiy na podzheludochnoy zheleze pri khronicheskom pankreatite [Pathogenetic substantiation of primary and repeated pancreatic operations in chronic pancreatitis]. Zhurnal "Annaly hirurgicheskoy gepatologii" - Journal "Annals of Surgical Hepatology”, 3, 80-88 [in Russian]. 


\title{
A. V. VOROBEI, A. CH. SHULEIKO, YU. I. VIZHINIS, N. A. LAGODICH
}

Belarusian Medical Academy of Postgraduate Education, Minsk, Republic of Belarus

\section{LASER TECHNOLOGY IN THE CHRONIC PANCREATITIS SURGERY}

The aim of the work: to study the efficiency of laser technology in the surgical treatment of chronic pancreatitis.

Materials and Methods. The study included 523 interventions for chronic pancreatitis, including 385 pancreatic resections. 131 surgical interventions were performed with our laser MUL-surgeon, including resection of the head of pancreas - 84, cylindrical virgungectomy -25 , double balloon enteroscopy procedures -4 .

Results and Discussion. Laser pancreatic resections in patients with chronic pancreatitis using a 1320 nm wave have significant advantages over the electrocoagulation. We revealed reducing blood loss and the level of severe postoperative complications. We received first positive results of using laser technology for performing double balloon enteroscopy procedures for correcting pancreatojunoanastomosis delayed postoperative complications. Laser radiation in the surgery of chronic pancreatitis is a promising direction in surgical pancreatology.

Key words: chronic pancreatitis; surgical laser; laser resection; virsungectomy; double ballon enteroscopy.

\section{О. В. ВОРОБЕЙ, А. Ч. ШУЛЕЙКО, Є. І. ВІЖІНІС, Н. А. ЛАГОДИЧ}

Білоруська медична академія післядипломної освіти, Мінск, Республіка Білорусь

\section{ВИКОРИСТАННЯ ЛАЗЕРНОГО ВИПРОМІНЮВАННЯ В ХІРУРГІЇ ХРОНІЧНОГО ПАНКРЕАТИТУ}

\begin{abstract}
Мета роботи: вивчити ефективність використання лазерних технологій при хірургічному лікуванні пацієнтів 3 хронічним панкреатитом.

Матеріали і методи. У дослідження включено 523 пацієнта, оперованих з приводу хронічного панкреатиту, у тому числі 385 з резекційними операціями. 3 застосуванням високоенергетичного лазера “МУЛ-хірург” виконано 131 хірургічне втручання, в т. ч. лазерну резекцію головки П3 - 84, лазерну циліндричну вірсунгектомію - 25, лазерні ДБЕ операції - 4.

Результати досліджень та їх обговорення. Лазерні резекції тканини підшлункової залози у пацієнтів з хронічним панкреатитом з використанням хвилі 1320 нм мають достовірні переваги над електрокоагуляційним способом, що полягають у зменшенні крововтрати, зниженні рівня тяжких специфічних післяопераційних ускладнень. Є позитивний досвід використання лазерних технологій при виконанні ендоскопічних операцій із застосуванням двобалонного ентероскопа для корекції післяопераційних ускладнень у зоні панкреатоєюноанастомозів. Використання лазерного випромінювання в хірургії хронічного панкреатиту є перспективним напрямком хірургічної панкреатології.
\end{abstract}

Ключові слова: хронічний панкреатит; хірургічний лазер; лазерна резекція; вірсунгектомія; двобалонна ентероскопія. 